\title{
Program Desa Berdaya Melalui Pengelolaan Keuangan Produk Lapak Desa Di Desa Kebontunggul Kecamatan Gondang Kabupaten Mojokerto
}

\author{
Aji Prasetyo ${ }^{1}$, Sugijanto $^{2}$, Yuni Sukandani ${ }^{3}$, Siti Istikhoroh ${ }^{4}$ \\ ${ }^{1234}$ Program Studi Akuntansi, Fakultas Ekonomi, Universitas PGRI Adi Buana Surabaya \\ E-mail : ajiprasetyo@unipasby.ac.id
}

\begin{abstract}
ABSTRAK
Desa Kebontunggul Kecamatan Gondang Kabupaten Mojokerto berkeinginan menjadi desa berdaya yang diawali dengan berhasilnya menumbuhkan potensi wisata berupa Lembah Mbencirang. Peran serta masyarakat desa merupakan kunci utama terwujudnya pemberdayaan ekonomi desa. Lapak-lapak desa merupakan perwujudan adanya peran serta masyarakat dalam menuju Program Desa Berdaya. Perlu adanya pengelolaan yang baik terhadap lapak-lapak desa untuk mewujudkan pemberdayaan desa yang optimal. Dalam rangka Tri Dharma Perguruan Tinggi, tim dosen Universitas PGRI Adi Buana Surabaya tergerak untuk melakukan pengabdian kepada masyarakat. Tujuan dari program ini adalah agar Desa Kebontunggul dapat mengoptimalkan produk lapak desa dengan pengelolaan keuangan yang sistematis guna menuju desa berdaya dan dapat meningkatkan kesejahteraan masyarakat di daerah tersebut. Hasil yang diperoleh dari kegiatan pengabdian kepada masyarakat ini adalah Desa Kebontunggul mempunyai produk unggulan jamu organik tunggul manik yang pemasarannya hampir di seluruh kota dan kabupaten di Jawa Timur, dan juga merupakan salah satu desa pemasok sayuran-sayuran segar di supermarket di Kota Mojokerto, selain itu juga banyak pemesanan bibit sayuran dari kabupaten lain seperti Kabupaten Sidoarjo, Gresik, dan Kota Surabaya. Masyarakat desa ini juga memiliki lapak desa yang cukup optimal di kawasan wisata Lembah Mbencirang. Adanya wisata ini memberikan pasar baru bagi masyarakat dalam bentuk foodcourt dan pusat oleh-oleh untuk menjual produk unggulan masyarakat setempat seperti Kripik Tortilla Jagung, Sirup Secang, Jamu Kunyit Asam dan lain-lain. Pengelolaan keuangan masyarakat desa Kebontunggul melalui lapak desa dilakukan dengan memahami dan mempraktikkan konsep Harga Pokok Penjualan (HPP) dan Break Event Point (BEP). Dengan memahami HPP dan nilai BEP, masyarakat akan mengetahui seberapa besar target penjualan produknya dalam satu bulan agar dapat balik modal dan berapa target penjualan produk agar memperoleh keuntungan yang diinginkan. Semakin banyak keuntungan yang diperoleh masyarakat, tentunya semakin menambah pendapatan desa Banjarsari yang berdampak pada kesejahteraan dan kesuksesan desa Banjarsari menjadi desa berdaya.

Kata kunci: desa berdaya, lapak desa, pengelolaan keuangan, desa Kebontunggul.
\end{abstract}

\section{ABSTRACT}

Kebontunggul Village, Gondang Subdistrict, Mojokerto Regency wishes to become a empowered village that was started with the success in growing tourism potential in the form of Mbencirang Valley. The participation of village communities is the main key to the realization of village economic empowerment. The village stalls are the embodiment of the role of the community in moving towards the Empowered Village Program. There needs to be good management of village shanties to realize optimal village empowerment. In the framework of the Tri Dharma of Higher Education, the lecturer team of PGRI Adi Buana University in Surabaya was moved to do community service. The purpose of this program is that Kebontunggul Village can optimize village stall products with systematic financial management in order to empower villages and improve the welfare of the people in the area. The results obtained from this community service activity are Kebontunggul Village which has superior products of herbal stumps which are sold in almost all cities and regencies in East Java, and is 
also one of the villages supplying fresh vegetables in supermarkets in Mojokerto, besides that also many vegetable seed orders from other districts such as Sidoarjo Regency, Gresik, and Surabaya City. The village community also has a village village that is quite optimal in the tourist area of Mbencirang Valley. The existence of this tour provides a new market for the community in the form of food court and souvenir center to sell superior products of local communities such as Corn Tortilla Chips, Secang Syrup, Turmeric Acid Herbs and others. The financial management of the Kebontunggul village community through the village shanties is carried out by understanding and practicing the concepts of Cost of Goods Sold (HPP) and Break Event Points (BEP). By understanding HPP and the value of BEP, the public will find out how big is the target of selling products in one month in order to be able to return the capital and how much the product sales target is to obtain the desired profit. The more benefits the community receives, of course, the more income the village of Banjarsari will have on the impact on the prosperity and success of the village of Banjarsari becomes a village of power.

Keywords: empowered village, lapak village, financial management, Kebontunggul village

\section{PENDAHULUAN}

Pembangunan desa khususnya di bidang perekonomian sangat bergantung pada perkembangan pelaku usaha yang ada di desa. Peran serta masyarakat desa merupakan kunci utama terwujudnya pemberdayaan ekonomi desa menuju desa berdaya. Desa berdaya adalah program pemberdayaan dalam cakupan wilayah desa (dan sebagian kelurahan), melalui pendekatan terintegrasi yaitu program capacity building (pembinaan masyarakat), ekonomi, pendidikan, kesehatan, lingkungan hingga kesiapsiagaan bencana, dengan target tumbuh dan berkembangnya kelembagaan lokal yang berdaya untuk mengatasi permasalahannya sendiri dengan menggabungkan kekuatan dan aset yang dimiliki, serta berkolaborasi dengan pihak lain terutama pemerintah desa (Rumah zakat, 2020).

Desa berdaya menjadi salah satu program pemerintah Jawa Timur untuk mengentaskan desa tertinggal dan sangat tertinggal di Jawa Timur agar menjadi desa berkembang, desa maju atau desa mandiri. Untuk mendukung penurunan angka kemiskinan, maka Pemerintah Provinsi Jawa Timur melalui Sasaran Indikator Kinerja Daerah yaitu Meningkatnya Pemberdayaan Masyarakat di Perdesaan berencana akan memasang target kinerja penurunan Desa Tertinggal dan Desa Sangat Tertinggal dalam RPJMD Th 2019-2024 (TKPK Jatim, 2020).

Lapak-lapak desa merupakan perwujudan adanya peran serta masyarakat dalam menuju Program Desa Berdaya. Lapak desa merupakan sebuah istilah untuk wadah atau fasilitas bagi masyarakat desa dalam memasarkan hasil produksi mereka. Kondisi pedesaan yang sebelumnya belum tersentuh teknologi komunikasi, hasil produksi dijual di pasar-pasar tradisional. Namun, mengimbangi perkembangan zaman, hasil produksi masyarakat desa mulai dipasarkan di situs-situs jual beli online. Dengan demikian, perlu adanya pengelolaan yang baik terhadap lapak-lapak desa untuk mewujudkan pemberdayaan desa yang optimal.

Desa Kebontunggul Kecamatan Gondang Kabupaten Mojokerto adalah desa yang memiliki potensi di bidang pertanian, perkebunan dan perikanan. Selama ini hasil 
panen dari pertanian, perkebunan dan perikanan pada umumnya dijual langsung kepada pembeli tanpa adanya pengelolaan lebih lanjut. Dampak dari tidak adanya pengelolaan lebih lanjut terhadap produk pasca panen, maka nilai jual dari hasil panen menjadi minim. Sebagian kecil masyarakat sudah mulai melakukan pengolahan produk pasca panen, contoh produk pasca panen yang sudah ada adalah kripik jagung. Hanya saja produk pasca panen yang telah dikelola masyarakat masih belum memiliki daya saing yang besar, karena produk diolah dengan apa adanya. Pengelolaan keuangan dalam penjualan produk masyarakat desa ini juga belum dikelola secara sistematis.

Pengelolaan keuangan desa adalah keseluruhan kegiatan yang meliputi perencanaan, pengangaran, penatausahaan, pelaporan, pertanggungjawaban, dan pengawasan keuangan desa (Arif, 2007). Keuangan desa merupakan faktor yang esensial karena dalam penyelenggaraan urusan rumah tangganya sendiri dibutuhkan adanya dana atau uang.

Pengelolaan keuangan desa adalah keseluruhan kegiatan yang meliputi perencanaan, pelaksanaan, penatausahaan, pelaporan, dan pertanggungjawaban keuangan desa. Dalam Peraturan Pemerintah Nomor 43 Tahun 2014 tentang desa Pasal 93 pengelolaan keuangan desa meliputi; perencanaan, pelaksanaan, pelaporan, dan pertanggungjawaban.

Keuangan desa diperoleh dari pendapatan desa melalui Rekening Kas Desa yang merupakan hak desa dalam 1 (satu) tahun anggaran yang tidak perlu dibayar kembali oleh desa. Pendapatan desa sesuai pasal 72 UU Desa bersumber dari; Pendapatan Asli Daerah (PAD), alokasi anggaran pendapatan dan belanja negara (Dana Desa), Bagian Hasil Pajak Daerah dan Retribusi Daerah Kabupaten/Kota, Alokasi Dana Desa, Bantuan Keuangan dari APBD Provinsi dan APBD Kabupaten/Kota, Hibah dan Sumbangan yang Tidak Mengikat dari Pihak Ketiga, dan Lain-lain Pendapatan Desa yang Sah. Pendapatan Desa diklasifikasikan menurut kelompok terdiri dari; (1) Pendapatan Asli Desa (PADesa), (2) Transfer, dan (3) Pendapatan Lain-Lain. Kelompok dana yang berasal dari masyarakat desa sendiri adalah PADesa yang salah satunya berasal dari hasil usaha seperti BUMDesa (BPKP, 2015).

Berdasarkan hasil survei tim pengabdian, kurangnya pengetahuan masyarakat terhadap pengelolaan produk pasca panen dan pengetahuan tentang pengelolaan keuangan dasar sistematis menjadi penyebab kurang bersaingnya produk-produk hasil olahan yang sudah ada dan penyebab kurang maksimalnya keuntungan yang diperoleh. Dengan demikian, Tim PPM melaksanakan kegiatan Pengabdian Masyarakat Fakultas Ekonomi Universitas PGRI Adi Buana Surabaya Tahun Akademik 2018-2019 dengan harapan dapat memberikan jalan keluar mengenai permasalahan yang dihadapi oleh para pelaku usaha di Desa Kebontunggul Kecamatan Gondang Kabupaten Mojokerto sehingga dapat meningkatkan kesejahteraan masyarakat. 


\section{METODE PELAKSANAAN}

Program Pengabdian Kepada Masyarakat ini fokus pada membentuk desa berdaya melalui produk lapak desa di Desa Kebontunggul Kecamatan Gondang Kabupaten Mojokerto. Harapan dari kegiatan ini adalah menuju desa yang mandiri dan kreatif dalam meningkatkan kesejahteraan masyarakat.

Agar dapat tercapai sasaran dan tujuan yang telah ditetapkan dalam program pengabdian kepada masyarakat di Desa Kebontunggul Kecamatan Gondang Kabupaten Mojokerto ini dilakukan penyuluhan oleh Dosen Fakultas Ekonomi yang dibantu oleh mahasiswa dengan pendanaan diperoleh dari Lembaga Penelitian dan Pengabdian Masyarakat Universitas PGRI Adi Buana Surabaya. Tahapan yang dilakukan dalam program ini; 1) survey lokasi untuk menentukan permasalahan dan potensi Desa Kebontunggul, 2) Koordinasi dengan tim pelaksana program, 3) Koordinasi dengan mahasiswa untuk membantu pelaksanaan program, 4) Pelaksanaan program pengabdian kepada masyarakat, 5) evaluasi hasil pengabdian kepada masyarakat.

\section{HASIL DAN PEMBAHASAN}

\section{Profil Lapak Desa di Desa Kebontunggul Kecamatan Gondang Kabupaten Mojokerto}

Mojokerto memiliki kekuatan potensi produk unggulan utamanya dari sektor pengelolaan pertanian dan ketersediaan sumber daya alam. Kekuatan potensi produk unggulan khas Mojokerto ini ditampilkan dari hasil pembangunan dengan pendekatan pengembangan Desa Model secara terpadu salah satunya adalah Desa Kebontunggul Kecamatan Gondang Kabupaten Mojokerto.

Desa Kebontunggul merupakan desa yang pernah mewakili Provinsi Jawa Timur untuk maju ke tingkat nasional dan menjuarai dalam bidang desa perintis agrowisata berbasis Tanaman Obat Keluarga (TOGA). Oleh karena itu pemerintah Kabupaten Mojokerto menunjukkan bukti nyata dalam pelaksanaan program pengembangan kawasan wisata dengan menunjuk Desa Kebontunggul sebagai Desa Wisata TOGA.

Salah satu obyek wisata edukasi di Kabupaten Mojokerto yang sangat menarik untuk dikembangkan adalah Obyek Wisata Edukasi Lembah Mbencirang yang terletak di Desa Kebontunggul Kecamatan Gondang Kabupaten Mojokerto. Obyek Wisata ini merupakan obyek wisata edukasi alam pertanian dengan latar belakang pemandangan alam Gunung Welirang dan Gunung Anjasmoro sehingga sangat potensial untuk dikembangkan. Edukasi yang diajarkan di obyek wisata ini meliputi edukasi pertanian TOGA, pembuatan jamu organik, pertanian sayuran organik dan hidroponik. Jenis-jenis edukasi yang ada di Obyek Wisata Edukasi lembah Mbencirang tersebut tidak lepas dari potensi yang dimiliki oleh Desa Kebontunggul (Maghfiroh, 2018).

Lembang Mbencirang ini pertama kali telah diresmikan oleh Bapak Siandi selaku Kepala Desa Kebontunggul. Lembah Mbencirang ini adalah salah satu tempat wisata baru yang ada di desa dengan memiliki beberapa wahana yang cocok untuk dicoba dari mulai anak-anak hingga dewasa. Akan tetapi kurangnya pelayanan serta kurangnya 
pembersihan membuat lembah mbencirang jarang dikunjungi oleh masyarakat umum (Widyastuty, et al., 2019).

Desa Kebontunggul juga mempunyai produk unggulan jamu organik tunggul manik yang pemasarannya hampir di seluruh kota dan kabupaten di Jawa Timur, dan juga merupakan salah satu desa pemasok sayuran-sayuran segar di supermarket di Kota Mojokerto, selain itu juga banyak pemesanan bibit sayuran dari kabupaten lain seperti Kabupaten Sidoarjo, Gresik, dan Kota Surabaya.

Selain memasarkan produknya hingga ke luar Mojokerto, masyarakat desa Kebontunggul ini juga diuntungkan dengan adanya wisata unggulan Lembah Mbencirang. Adanya wisata ini memberikan pasar baru bagi masyarakat dalam bentuk foodcourt untuk menjual produknya dan menambah penghasilan. Dengan adanya foodcourt dan pusat oleh-oleh ini, dapat menjadi lapak desa untuk memasarkan produk unggulan masyarakat setempat seperti Kripik Tortilla Jagung, Sirup Secang, Jamu Kunyit Asam dan lain-lain (Al-Karawangi, 2019).

\section{Membentuk Desa Berdaya Melalui Pengelolaan Keuangan Produk Lapak Desa di Desa Kebontunggul Kecamatan Gondang Kabupaten Mojokerto}

Produk lapak desa Kebontunggul yang dipasarkan melalui pasar desa, kawasan wisata, online, dan lainnya sangat membantu perekonomian masyarakat desa. Untuk lebih mengoptimalkan pengelolaan keuangan masyarakat melalui produk lapak desa, maka perlu dipahami terlebih dahulu tentang konsep Harga Pokok Penjualan (HPP) dan Break Event Point (BEP). Konsep HPP dan BEP ini juga dapat diterapkan oleh masyarakat yang memiliki usaha.

Bagi produsen, sebelum menentukan harga barang yang akan dijual kepada konsumen, maka ia perlu mengetahui terlebih dahulu harga pokok produksinya (HPP). HPP merupakan keseluruhan harga dari harga baku, pengolahan, hingga barang jadi. HPP juga dapat dipahami sebagai harga beli dari supplier. Setelah diketahui HPP, kemudian ditentukan keuntungan yang diinginkan (Kuswadi, 2005).

Rumus HPP:

\section{HPP : Material + Labour + Overhead + Inventori Awal-Inventori Akhir}

Diketahuinya HPP dan keuntungan yang diinginkan, maka produsen dapat menentukan harga jual produknya agar dapat menutup seluruh biaya HPP dan memperoleh keuntungan yang diinginkan.

Adapun Break Event Point (BEP) atau dikenal dengan titik impas, yaitu titik di mana penjualan dan biaya yang telah dikeluarkan telah sama atau impas. Dalam perhitungan BEP tidak ada untung atau rugi, karena jumlah uang masuk dan keluar benar-benar sama persis. Atau istilah umumnya adalah balik modal (Hansen, 2006).

Untuk mengetahui berapa BEP, cukup dengan membagi HPP produksi sebulan dengan harga jual yang telah ditetapkan. HPP dan BEP ini penting untuk para pelaku usaha. Bagi masyarakat desa Kebontunggul khususnya, dengan mengetahui HPP dan nilai BEP, masyarakat akan mengetahui seberapa besar target penjualan produknya 
dalam satu bulan agar dapat balik modal dan berapa target penjualan produk agar memperoleh keuntungan yang diinginkan.

\section{DAMPAK DAN MANFAAT KEGIATAN}

Masyarakat desa Kebontunggl telah memiliki produk-produk andalan yang dapat dipasarkan di lapak desa. Lapak desa Kebontunggul saat ini telah terwujud seperti yang ada di kawasan wisata desa Lembah Mbencirang. Namun demikian, masyarakat desa Kebontunggul masih minim pengetahuan dan pemahaman tentang pengelolaan keuangan dalam produksi dan penjualan. Oleh karena itu, dalam program Pengabdian Masyarakat Fakultas Ekonomi Universitas PGRI Adi Buana Surabaya memberikan seminar sekaligus pelatihan pengelolaan keuangan dengan materi Harga Pokok Penjualan (HPP) dan Break Event Point (BEP). HPP dan BEP merupakan materi dasar dalam pengelolaan keuangan sebagai perhitungan untuk mendapatkan besaran laba yang diinginkan dari proses produksi hingga penjualan.

Dengan mengetahui dan memahami konsep HPP dan BEP yang disampaikan dalam program Pengabdian Masyarakat ini, masyarakat desa Kebontunggul dapat menghitung HPP dan BEP untuk mengelola keuangan usaha produksi yang mereka pasarkan di kawasan wisata Lembah Mbencirang maupun di area lainnya seperti pasar-pasar desa hingga luar desa. Masyarakat desa Kebontunggul secara garis besar telah dapat menghitung HPP dan BEP dari usaha produksi mereka sebelum produk dijual di pasaran. Masyarakat merasa terbantu karena mereka dapat menentukan harga jual produk yang dapat menghasilkan laba sesuai keinginan.

\section{SIMPULAN}

Salah satu pilar yang mendukung perekonomian masyarakat desa Kebontunggul selain dari wisata Lembah Mbencirang adalah penjualan produk-produk lapak desa yang beragam, mulai dari bibit sayuran, kripik Tortilla Jagung, Sirup Secang, Jamu Kunyit Asam dan lain-lain. Untuk mengoptimalkan penjualan produk-produk tersebut, masyarakat perlu memahami konsep HPP dan BEP yang merupakan konsep perhitungan keuangan agar usaha yang dikelola masyarakat mendatangkan keuntungan yang mereka inginkan. Setiap masyarakat perlu mengetahui, memahami, dan mempraktekkan konsep HPP dan BEP untuk setiap penjualan produk yang dihasilkannya. Semakin banyak keuntungan yang diperoleh masyarakat, tentunya semakin menambah pendapatan desa Kebontunggul yang berdampak pada kesejahteraan dan kesuksesan desa Kebontunggul menjadi desa berdaya. Pemberdayaan masyarakat desa melalui program Pengabdian Masyarakat ini masih jauh dari sempurna. Pengabdian masnyarakat dapat dilakukan dengan program-program lain secara luas oleh peneliti mandiri, kelompok organisasi, maupun civitas akademika perguruan tinggi lain. Khususnya di desa Kebontunggul, dalam bidang ekonomi, masih banyak potensi dan permasalahan yang dapat dikelola dengan baik, seperti menggali kemampuan masyarakat mengolah hasil bumi desa dan kreativitas masyarakat maupun memberikan pelatihan produksi yang lebih efisien serta pemasaran yang lebih luas dan mudah. 


\section{UCAPAN TERIMA KASIH}

Program Pengabdian Masyarakat ini tidak dapat berjalan lancar dan sukses tanpa bantuan dari berbagai pihak. Oleh karena itu, dalam kesempatan ini kami penulis menyampaikan banyak terima kasih kepada:

1. LPPM Universitas PGRI Adi Buana Surabaya sebagai pemberi dana pelaksanaan program Pengabdian Masyarakat

2. Dekan serta seluruh dosen tim Pengabdian Masyarakat Fakultas Ekonomi Universitas PGRI Adi Buana Surabaya atas kerja samanya melaksanaan program ini hingga selesai

3. Pemerintah dan masyarakat Kabupaten Mojokerto khususnya masyarakat desa Kebontunggul Kecamatan Gondang atas kerja samanya menerima kami para dosen untuk melaksanakan program Pengabdian Masyarakat ini.

\section{DAFTAR PUSTAKA}

Al-Karawangi, A. 2019. "Fasilitas Foodcourt Tambah Daya Tarik Kawasan Wisata Lembah Mbencirang" dalam https://www.indonesiana.id/read/134248/fasilitasfoodcourt-tambah-daya-tarik-kawasan-wisata-lembah-mbencirang.

Arif, M. 2007. Tata Cara Pengelolaan Keuangan Desa Dan Pengelolaan Kekayaan Desa Pekanbaru. ReD Post Press.

BPKP. 2015. Petunjuk Pelaksanaan Bimbingan \& Konsultasi Pengelolaan Keuangan Desa. Deputi Bidang Pengawasan Penyelenggaraan Keuangan Daerah.

Hansen. 2006. Akuntansi Manajemen. Jakarta: Salemba Empat.

Kuswadi. 2005. Akuntansi Keuangan. Jakarta: Salemba Empat.

Maghfiroh, N. L. 2018. Strategi Pengembangan Obyek Wisata Edukasi Lembah Mbecirang di Desa Kebontunggul Kecamatan Gondang Kabupaten Mojokerto. Swara Bhumi, 5 (7).

Rumah Zakat. 2020. "Desa Berdaya" dalam https://desaberdaya.id/.

TKPK Jatim. 2020. "Desa Berdaya" dalam http://tkpk.jatimprov.go.id/projects/desaberdaya/.

Widyastuty, A. A. S. A., et al. 2019. Pemberdayaan Pemuda Karang Taruna Melalui Program Remaja Peduli Lingkungan Desa Wisata Kebontunggul. Penamas Adi Buana, 3 (1). 